\title{
The results of the first periodical testing vent-panels (VP)
}

\author{
Yuri Polandov, Denis Kukin*
}

Moscow State University of Civil Engineering, Jaroslavskoe Shosse 26, Moscow, Russian Federation

\begin{abstract}
The article is devoted to analysis of obtained during testing of sandwich panels and insulating glass as VP results. Here are the details on the first periodic test VP method GOST R 56289-2014 «Design translucent legkousvaivaemyh for buildings» using measuring instruments and testing equipment according to this standard, and, accordingly, the results of tests with additional observations obtained during the research.
\end{abstract}

\section{Introduction}

In recent years in construction are widely used lightweight wall materials, such as sandwich panels and glass units (hereinafter the Panel). Faced with a clear need for use as VP. However, we know the effect of material density VP on its effectiveness as a means of protection in gas explosions at the premises: the greater the density, the higher the pressure the explosion. Obviously, that is confirmed by the Standard certification is necessary in such cases such as VP remedies. In civil engineering at the Institute for integrated security for the first time in Russia there are all conditions for production acceptance and periodic tests such VP. In the article the results of Russia's first periodic tests such VP.

It should be noted that the Russian demands to VP does not deal with sandwich panels. For example, in the rules [1] considered requirements for Windows made of glass, so they specify minimum window size and requirement of single of their covers. But it should be noted that these Regulations apply only to the boiler. Another famous document, such as a standard [2], contains requirements for only one VP class, namely to devices of translucent materials (DTM), i.e. to Windows and modern so called restful. Despite the fact that it discussed in detail various aspects of the technical requirements to this class of VP, wonderfully issue limiting their density does not pay attention. Even in one document Standard [3], describes this type of VP test conditions (i.e., from DTM) for triggering at a given pressure, the conditions according to requirement should be close to reality. The dignity of this standard include what he, in spite of its name, and formally against only the VP from DTM, methodology and tools described in it have substantial community and can be applied to all known types of VP.

It follows from this that, at this stage, the question of the applicability of the sandwich panels as VP should be determined in each case, the designers. It is clear that, as a result of obtaining evidence of their effectiveness, obtained by direct testing, for example, according to [3].

The number of research papers in Russia regarding the topics raised is very limited. You can mark only 2 work, this dissertation $(\mathrm{PhD})$ [4-7], which dealt with mathematical models and experimental results of the development process of gas explosion at operation VP. Unfortunately, the first job you can note the lack of skilled works on VP, close in size to the actual, and in the second-it can be seen that the results of an experiment on SP real size seem unconvincing.

In Europe and the United States panels have been used earlier than we have. To date, there are enough serious conducted studies on their use as VP. For the most part, this issue is considered solved, and its solution is reflected in the relevant normative instruments $[8,9]$ in the sections dealing with the security device in rooms with gas explosions. Incidentally, they also recommend the use of specific gravity with VP, specified in our materials. But these documents are summarized and the rationale for this restriction, which is not in our.

In addition to standards, there are also work [10-15] which are developing as mathematical models, sound empirical data that describe the behavior of the explosion, and a description of the physical processes occurring in the process of exploding.

Naturally, in addition to the formal aspects of the tests we accompanied them with additional research. In our opinion is of interest in practical and scientifically obtained experimental results.

Test task: practicing methods of testing; verification of the claimed efforts autopsy VP in the dynamics of explosion; Evaluation of the effectiveness of the VP as a remedy when the gas blast.

\section{Method of testing}

The tests were carried out on the test bench vent-panels (VP). The installation consists of two chambers. The main explosion Chamber, standards compliant, has dimensions $(2000 \times 2000 \times 2000) \mathrm{mm}$. Inside the installed small explosion

\footnotetext{
${ }^{*}$ Corresponding author: dekuk07@,mail.ru
}

(C) The Authors, published by EDP Sciences. This is an open access article distributed under the terms of the Creative Commons Attribution License 4.0 (http://creativecommons.org/licenses/by/4.0/). 
chamber size $(1000 \times 1000 \times 1000 \mathrm{~mm})$, which supplied propane gas in volume sufficient to produce stoichiometry mixtures with air. There, in a small Chamber positioned fan for gas mixing and ignition device. To ensure the isolation of small volume Chambers in the cooking process blend side, open and facing to the escape hole, blast Chamber closed the curtain is a reusable action. When the screen opens and the gases from the small camera coming into explosive, increasing the pressure there. Increase pressure ensures destruction sites fastening of panels and reset them.

When testing was carried out two major measurement parameters characterizing the trigger nodes bracing of ventpanels: pressure inside the blast Chamber and the beginning of motion design. For measurements were used the following measuring tools: pressure sensor, power supply and analog-to-digital converter la USB 20, production of company "Rudnev-Shilyaev"; the device, move the sensor type gap "lever" and video recording; personal computer.

On a computer that has produced a record of the following signals: from a pressure sensor, the signal "explosion" combined with a signal lamp, signal "open circuit" and displacement sensor. When processing and conversion of analogue signals used guaranteed manufacturers specifications and codes for them, and when you build charts-Excel 2010.

Of course, for spending explosion used tools such as stopwatches, measuring rulers, sensors, computer codes, ADC and programs for data processing, which have confirmed with certificates and manufacturers because organizations. But it is difficult to list other parameters and conditions that, in one way or another, affect the outcome of the explosion. Consider in advance the result of sharing of devices and means of attorneys, as well as the impact of the entire set of factors is almost impossible, therefore, to assess the impact of an uncontrolled experiment on the outcome of the total conducted the installation tests. We conduct them in quantities of 10 experiments during one period of time. The results are given in Figure 1. Visible to their acceptable reproducibility. The results obtained after installation panels, obviously, are the result of it is the installation of the panels, rather than by some other factor. Therefore, the difference in received data can be interpreted.

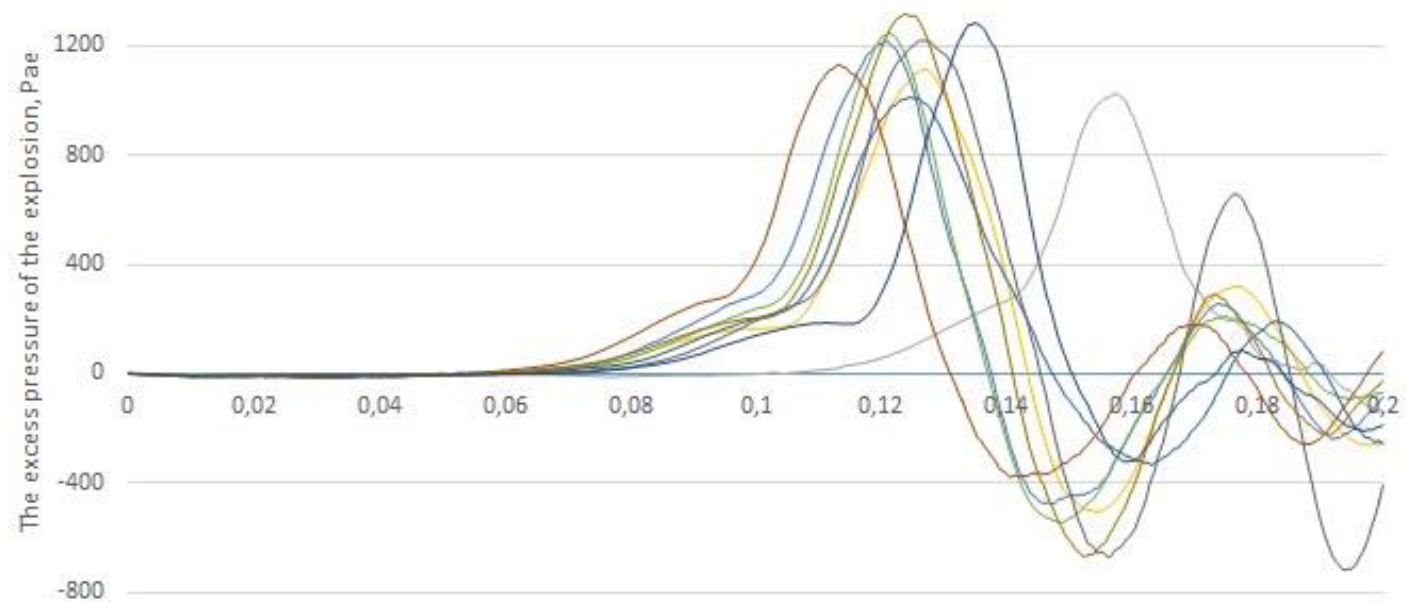

Time, sec

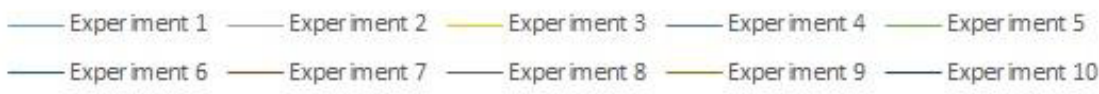

Fig.1 Schedule installation tests

\section{The results of the tests}

\subsection{The results of the tests of sandwich panels as VP}

Tested characteristics of sandwich panels. The Panel consists of steel plates (facing) thickness of $0.8 \mathrm{~mm}$, inside of which is thermal insulation (insulation) on the basis of mineral wool. Outside sheets coated with polymeric material in white color. Weight of panels with dimensions (1000x1640) mm thick $100 \mathrm{~mm}$ was $30.4 \mathrm{~kg}$. The total number of nodes, retention, collapsing in the explosion-4, they placed at a distance of $60 \mathrm{~mm}$ from the edges of the Panel. Each node consists of a screw with a diameter of $10 \mathrm{~mm}$, inserted in a hole with a diameter of $10.5 \mathrm{~mm}$ Panel head outdoors, indoors on it attached to the sleeve, which is on the housing of the camera. In the sleeve and its axis perpendicular to the bolt drilled a hole with a diameter of $1.0 \mathrm{~mm}$, which are inserted steel wire with a diameter of $0.75 \mathrm{~mm}$ flanged brand. In the case of explosion inside Panel begins with it moves relative to the bolt sleeve, cutting off the wire. Force cut wire in field 8 is an obstacle that must overcome the pressure of the blast. 
There are two unknown factors when gathering with fixation points in case of explosion may cause skewing sandwich panels, that can affect the outcome of the test. Firstly, when a large number of destructible items (8 slices) is quite reason, the question of their simultaneous firing. And, secondly, it is obvious that the weight of the load is distributed between bolts unevenly, which can lead to different values of the forces of friction of rest between bolts and bushings that can also affect the results of the experiment.

Tests of sandwich panels made using the fan unit. Objective test was to evaluate the pressure at which collapse fixture equal to 5000 Units. The footage shows how the moves ploskoparallel'no installation after the explosion. Data processing showed that it moves at an average speed of $18 \mathrm{~m} / \mathrm{s}$. Other test data are shown in Figure 2. You can see that the destruction of the attachment node occurs at the same pressure of 4500 Units in both experiments. On the face of a good repeatability. Concluded that the fixture are destroyed at a pressure closer to the declared.

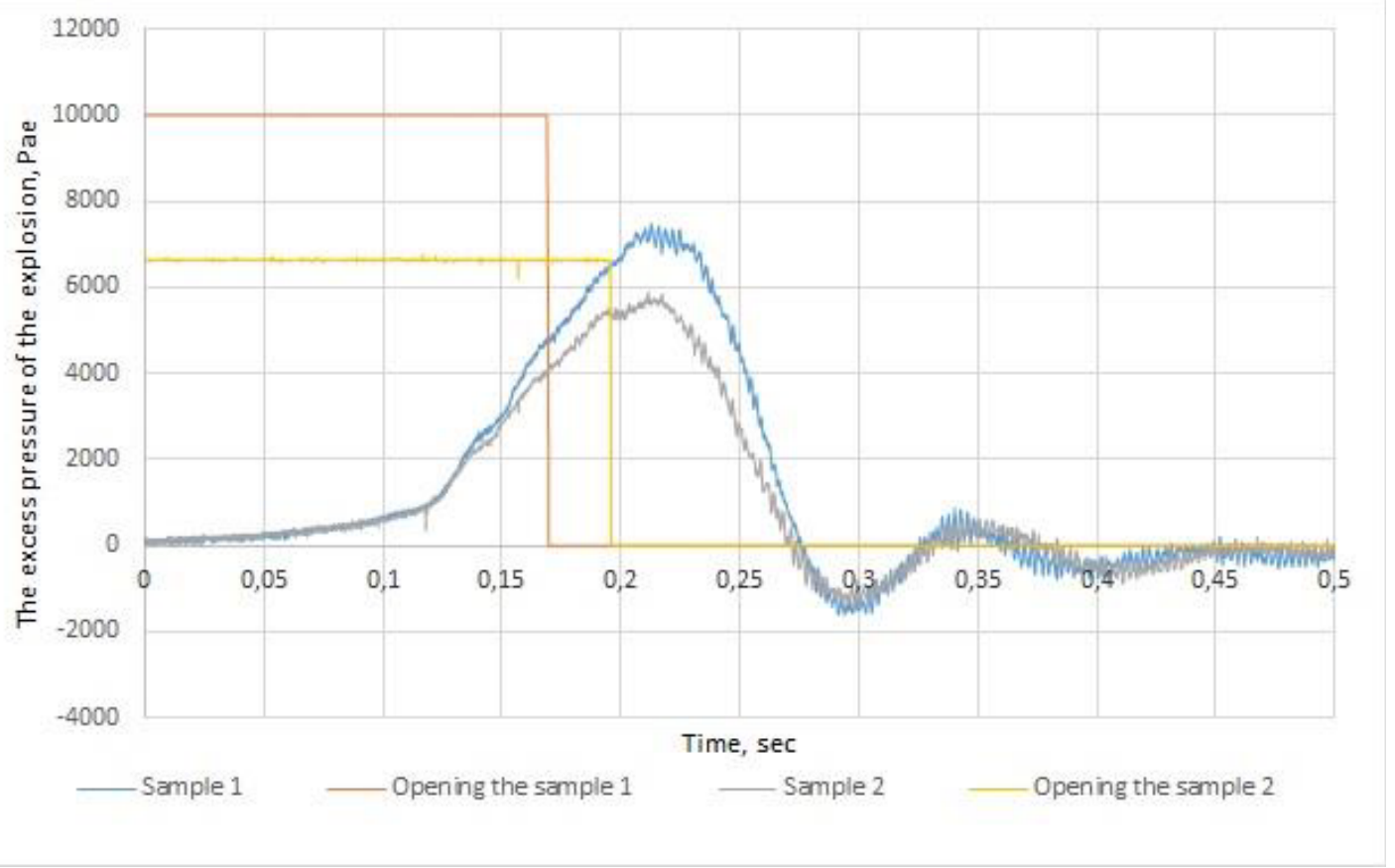

Fig.2 Test schedule of sandwich panels

Noteworthy that the pressure in the Chamber continues to grow slightly after the destruction of the attachment node, although according to estimations it must fall with the beginning reset panels.

Storyboard videos tests of sandwich panels is shown in Figure 3. 

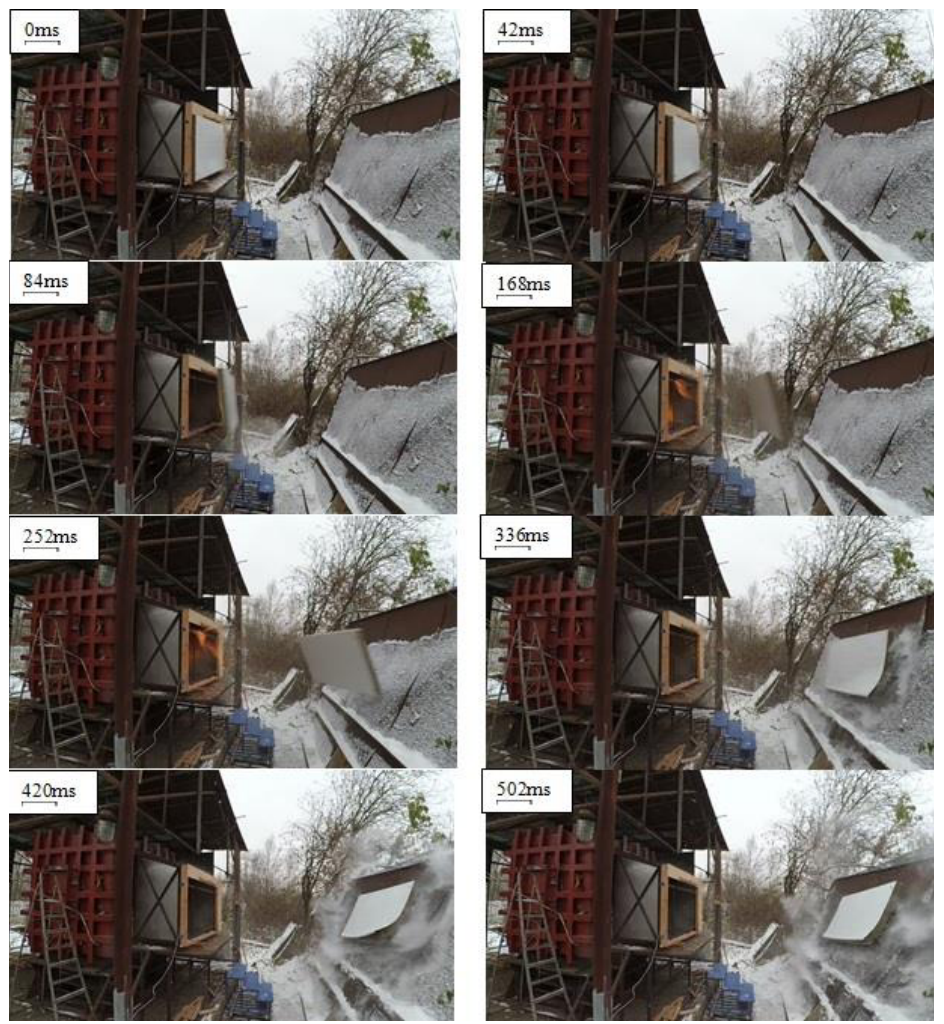

Fig.3 Video release of sandwich-panels with the explosion

\subsection{The results of the tests of insulating glass as VP}

Characteristics of the tested insulating glass. The specimen is a vent-panels (VP) in the form of a window frame with two double-glazed Windows with dimensions (1650hh1450) mm. Frame made of aluminum profiles post and beam system. F50:

-Reinforced stand $80 \mathrm{~mm}$ ALT. (F) $50.0103+$ ALT. (F) 50.0303

-Reinforced bolt $85 \mathrm{~mm}$ ALT. (F) $50.0206+$ ALT. (F) 50.0303

-fill-single chamber energy-saving glazing thickness of $24 \mathrm{~mm}(6 / 12 / 6)$.

Weight of a double-glazed window in the collection stood at $50.0 \mathrm{~kg}$. Panel sealed metal waste hole blast Chamber in six points. In the opening holes top and bottom patch installed lateral corners $(75 \times 75 \times 5) \mathrm{mm}$ using wedge anchors "HILTI" length $160 \mathrm{~mm}$ with step of $600 \mathrm{~mm}$. Through the special holes in the corner of the $300 \mathrm{~mm}$ increments the frame inserted self-tapping screw-Stud, then for the centric fitting guide Bush. After putting all six landing points on studs were wrapped fluorine plastic washers F4. After mounting the frame inserted double glazing using the clamping plates. The principle of operation of the VP was founded at offset frames with glazing (destruction of the attachment node VP)-roll it out when exposed to excessive pressure.

Held only 3 tests. Objective test was to evaluate the pressure at which collapse fixture, equal to 700 Units. The first test of insulating glass units conducted using fan console showed a strong influence on the development process of the explosion and the test results. The remaining 2 explosion taken place without diffuser and their results are given in Figure 4. It can be seen that glazing all 6 mounting nodes are destroyed at the same time, and the package moves almost ploskoparallel'no at an average speed of $16 \mathrm{~m} / \mathrm{s}$ shows that the destruction of the attachment node occurs at the same pressure of 2500 Units in both experiments. On the face of a good repeatability. Concluded that the fixture are destroyed at a pressure that varies more than three times with a declared, but is below the acceptable for categories a and $b$ class premises on fire safety. 


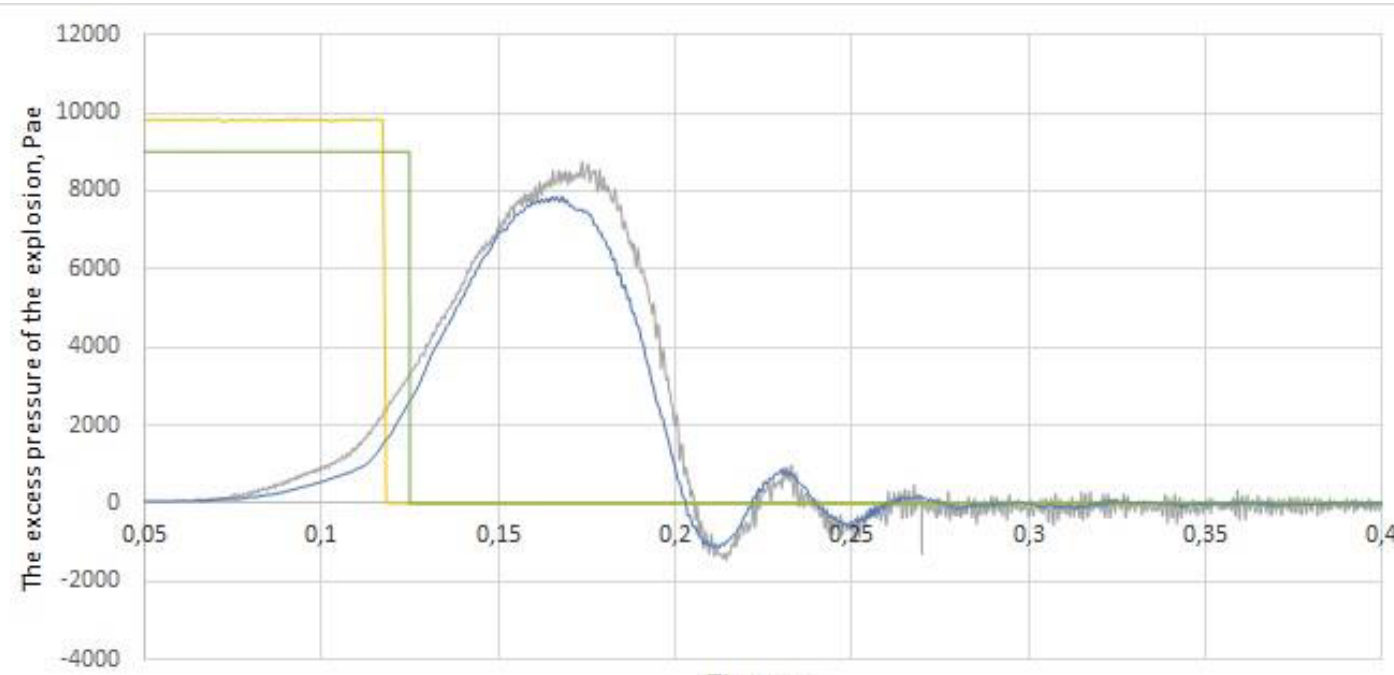

Time, sec

- Sample 1 Opening the sample 1 - Sample 2 Opening the sample 2

Fig. 4 Test schedule of double-glazed Windows

Noteworthy, that in this case the Chamber pressure continues to grow after the destruction of the attachment node, although according to estimations it must fall with the beginning reset panels.

Storyboard videos tests of sandwich panels is shown in Figure 5.

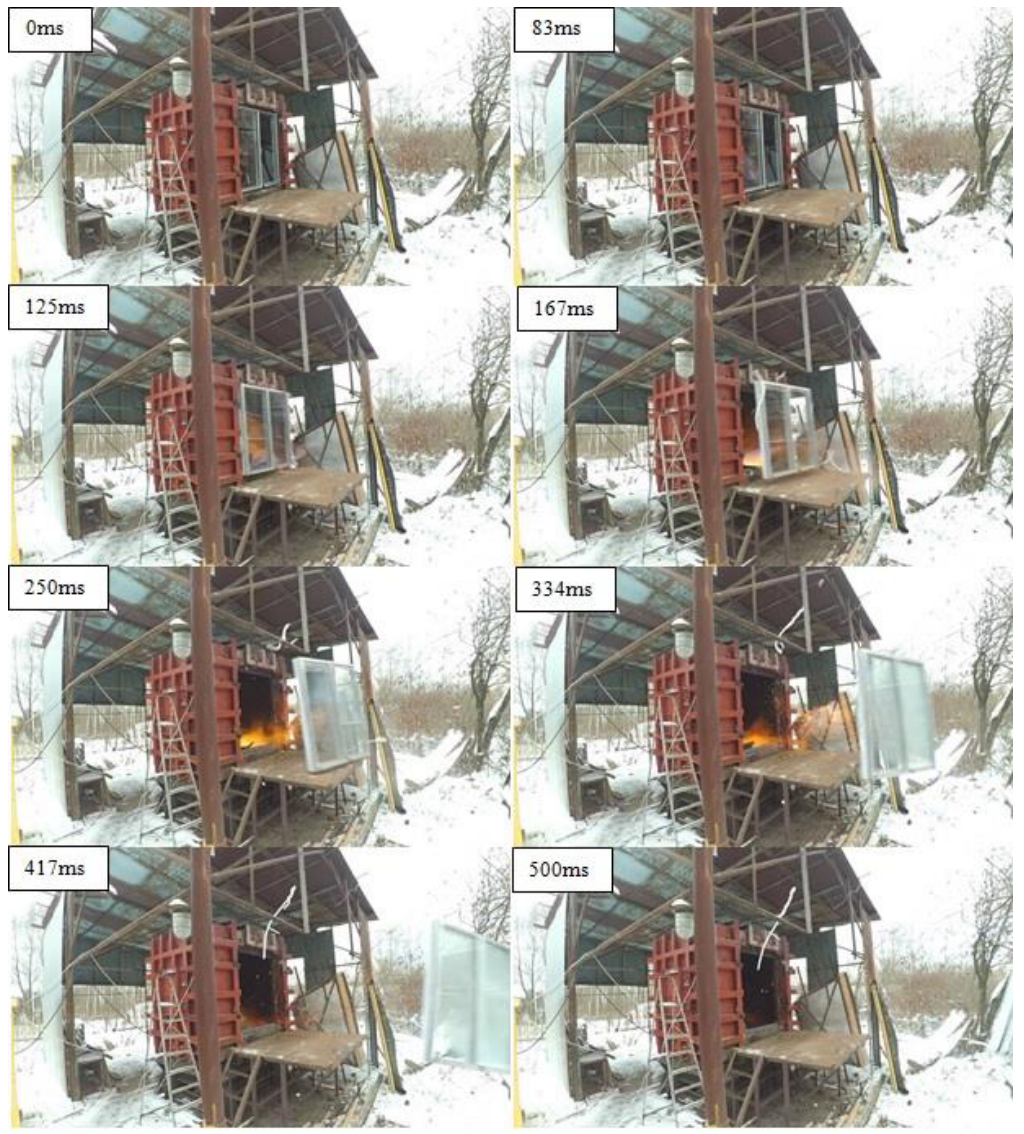

Fig. 5 Video release of sandwich-panels with the explosion 
The move on the gauge shows that the destruction of sites of fastening takes place in several stages, among which, in our view, there are several stages: sampling clearances on the node are attached; the existence of a plot by the elastic deformation of the specimen and fluidity and destroyed material attachment sites. The first $10 \mathrm{~cm}$ panel movement is accompanied by a build-up of pressure in the Chamber. The sensor in the future due to the fact that the Panel has gone.

\section{Conclusion}

Based on the results of the works you can make the following conclusions:

- Reproducibility shows the adequacy of instrumentation and test management system-wide;

- The results of the test panels in one case showed convergence with data stated in another case-non-conformity;

- Revealed an interesting effect is to increase pressure on a certain period of time after the initiation of the dumping of panels. In our opinion, should evaluate the effectiveness of panels as VP incl. plot increases in pressure after the destruction of sites of attachment. The reason for the growth of pressure after the destruction sites should install more fasteners.

\section{References}

1. GOST R 56288-2014. Designs windowing fiberglass legkosbrasyvaemye for buildings. Technical conditions. 07.01.2015 entered. Moscow, Standartinform, (2014)

2. $\quad$ Snip II-35-76 *. Boiler installation. Section 3. Objectively-planning and design solutions. -Enter. 01.01.1978.m.: Stroiizdat, (1977)

3. GOST R 56289-2014 "Designs for buildings" legkosbrasyvaemye translucent. Test methods for impact internal emergency Moscow blast Standartinform (2015)

4. A.A. Komarov, A.Y. Mishuev, The dissertation on competition of a scientific degree of doctor of technical sciences-"prediction of loads from emergency deflagracionnyh blasts, and assessment of the impact of their effects on buildings and structures; Moscow (2001)

5. E.Y. Salymova, V.A. Gorev v.a.-Dissertation on competition of a scientific degree of candidate of technical sciences-«Dynamics hazards in buildings with protecting structures from the three-layer sandwich panels in fires and explosions; Moscow (2015)

6. Yu.N. Shebeko, A.Ya. Korolchenko, S.G. Tsarichenko,V.Yu Navtsenya, V.L. Malkin, Combustion, Explosion, and Shock Waves, 25 (3), 289-292 (1989)

7. Yu. N. Shebeko, A. Ya. Korolchenko, E.D. Zamishevski, A.V. Trunev, V.Yu. Navzenya, A.A. Zaitzev, Combustion and Flame, 117 (1-2), 438-440 (1999)

8. EN 14994:2007. Gas explosion venting protective systems.

9. NFPA 68. Standard on explosion protection by deflagration venting. 2007 Edition. - Quincy, MA: National Fire Protection Association (2007)

10. R. Siwek, R, O. Scov, VDI Berichte, 701, 569-616 (1988).

11. H.S. John Lee The gas dynamics of explosions 216 (2016)

12. A.F. Sharovarnikov, D.A. Korol'chenko, Applied Mechanics and Materials, 475-476, 1344-1350 (2014)

13. D. Korolchenko, S. Voevoda, MATEC Web of Conferences 86 (2016)

14. Y. Polandov, A. Korolchenko, S. Dobrikov, MATEC Web of Conferences, 86 (2016) 